\title{
Multifunctional fabrics finished using electrosprayed hybrid Janus particles containing nanocatalysts
}

Jiangsong Hou, ${ }^{a}$ Yaoyao Yang, ${ }^{a}$ Deng-Guang Yu $,{ }^{a},{ }^{*}$ Zezhong Chen, ${ }^{a} \mathrm{Ke}$

Wang, ${ }^{a}$ Yanan Liu, ${ }^{a}$ and Gareth R. Williams ${ }^{\mathrm{b}}$

${ }^{a}$ School of Materials Science \& Engineering, University of Shanghai for Science \& Technology, Shanghai 200093, China.

${ }^{\mathrm{b}}$ UCL School of Pharmacy, University College London, 29-39 Brunswick Square, London WCIN 1AX, UK

* Corresponding author:

Prof. Deng-Guang Yu

516 Jungong Road, Shanghai 200093, China

E-mail: ydg017@usst.edu.cn

Tel/Fax: +0086-21-55270632 


\section{ABSTRACT}

There is great market demand for fabrics equipped with multiple functionalities. However, most methods to impart these properties to a pristine fabric are complicated, time-consuming, and expensive. In this work, Janus particles with one side comprising $\mathrm{TiO}_{2}$ nanoparticles (NPs)-PVDF (poly (vinylidene fluoride)) and the other an epoxy resin (TPE) were deposited on a fabric surface. The aim was to endow the fabric with superhydrophobic, UV resistance, and antimicrobial properties. The Janus particles were firmly attached to the fabrics through the adhesion effects of the epoxy resin. Characterization by XRD, SEM, EDX, and FTIR verified the successful finishing of the fabric with TPE particles. The ultraviolet protection factor increased from 7.86 for the pristine fabric to 733 after finishing. The finished fabric also exhibited superhydrophobic properties, with a water contact angle of $152^{\circ}$. Further, the coating of the fabric did not hamper its gas permeability. Potent antibacterial properties against E. coli were observed owing to the antibacterial properties of $\mathrm{TiO}_{2}$ under irradiation by UV light. The protocols reported here provide a new platform for the nano-finishing of fabrics, allowing new functions to be imparted without compromising the fabric's original properties.

KEYWORDS: Janus particle, side-by-side electrospraying, nano-finishing, multifunctional fabrics 


\section{Introduction}

Multifunctional fabrics with waterproof, UV-resistant and antibacterial properties have a wide range of potential applications in clothing, medical instruments, and pharmaceutical coatings [1-8]. Such materials can block water droplets from penetrating, avoid UV damage to the skin, and inhibit the growth of bacteria [9-14]. In general, the endowment of multiple functions requires the combination of hydrophobic surfaces with micro/nanoscale structure, low surface energy, and auxiliary components [15-19]. Beyond traditional processing methods, researchers have proposed various strategies such as layer-by-layer assembly [20], dip coating [21], chemical vapor deposition [22], and etching [23-26] as routes to impact additional functionality. Although these methods have been shown to be successful, there remains a distinct need to develop improved finishing methods and to optimize the properties and performance of the finished textiles. Furthermore, many functions of the finished textiles are achieved by sacrificing the innate comfort, permeability and other physical characteristics of the pristine textiles. Thus, a major challenge posed to researchers is to impart the designed functionality without compromising the innate characteristics of the textiles. New methods that can be employed to deposit different functional ingredients on the textile fibers while retaining the initial porous structure are much desired.

In the literature, inorganic nanoparticles (NPs) and nanotubes made of materials such as $\mathrm{SiO}_{2}[27,28], \mathrm{ZnO}$ [29-32], $\mathrm{Ag}$ [33-37], $\mathrm{CuO}$ [38], $\mathrm{MoS}_{2}$ [39], and $\mathrm{TiO}_{2}$ [40- 
44] have all been demonstrated be suitable for the preparation of functional fabrics [ 45 ,

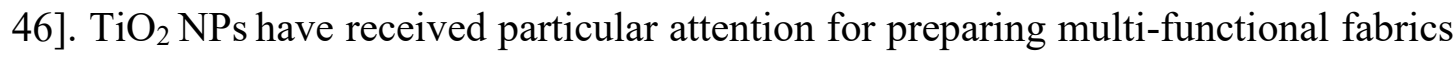
owing to their stability, high surface activity, non-toxic and biocompatible nature, and antibacterial properties after irradiation with UV light $[47,48]$. However, the finishing processes required to deposit them are multiple-step, time-consuming, and can make it difficult to ensure a high-quality and reproducible product $[49,50]$. For instance, superhydrophobic fabrics having UV-shielding and antibacterial properties were prepared by firstly coating with $\mathrm{TiO}_{2}$ and then solution soaking with a fluoroalkyl silane to impart superhydrophobic properties $[51,52]$.

Alternative approaches to functionalizing fabrics include electrospraying and electrospinning. Both are electrohydrodynamic atomization (EHDA) techniques through which particles and fibers at the micro/nano- scale can be produced in a straightforward single-step process [53-57]. The simplest experiment involves the application of electrical energy to a polymer/functional component solution, resulting in rapid solvent evaporation and the formation of solid composite materials. Recent developments in the field have led to multiple-fluid EHDA methods, providing a number of novel nanoscale products. These methods have permitted the fabrication of a series of complex nanostructures, such as core-shell, Janus and combined structures $[58,59]$. Using multiple-fluid EHDA has also been shown to allow the handling of fluids which cannot be processed into solid fibers or particles alone [60]. 
Janus products have anisotropic two-sided structures, and thus exhibit two different sets of surface features [61-65]. This can be exploited to encapsulate different functional additives and achieve synergistic effects [66-68]. Small particles having a high degree of uniformity in size can be uniformly dispersed on a fabric surface [69, 70]. Side-by-side electrospraying is able to produce Janus particles, with considerable control over particle size. Thus, it can be hypothesized that side-by-side electrospraying has potential applications as an effective nano-finishing method for fabrics.

In this work, a side-by-side electrospraying process was developed using an acentric spraying head. An epoxy/TETA mixture was used as one of the working fluids, and coprocessed with a $\mathrm{TiO}_{2}-\mathrm{PVDF}$ suspension. The finished fabrics were characterized in detail and their functional performance explored.

\section{Experimental methods}

\subsection{Materials}

Epoxy (Epikote-828) was obtained from Momentive Specialty Chemicals, USA. PVDF (solef ${ }^{\circledR} 1010$ poly(vinylidene fluoride) ) with a molecular weight of $1 \times 10^{5} \mathrm{~g} \cdot \mathrm{mol}^{-}$

${ }^{1}$ was supplied by Solvay (Belgium). N, N-dimethylacetamide (DMAc) and acetone were obtained from the Sinopharm Reagent Co (China). The curing agent triethylenetetramine (TETA), was purchased from Shanghai Guofa Plastics Co., Ltd. (China). Titanium dioxide (P25, $\geq 99.5 \%$, ) was obtained from Degussa (Germany). Titanium dioxide $\mathrm{P} 25$ is a nano-sized white powder comprising anatase to rutile at about 80/20 w/w. A PET (polyethylene terephthalate) microfiber dust-free fabric was 
obtained from a local supermarket. LB Broth was supplied by Thermo Fisher Scientific (China). Anhydrous ethanol was bought from the Sinopharm Chemical Reagent Co., Ltd. (China). All reagents were used as received without further purification.

\subsection{Preparation of multi-functional fabrics}

Solutions for electrospinning were prepared as follows. $10 \%(\mathrm{w} / \mathrm{v})$ PVDF was added to a $6: 2 \mathrm{v} / \mathrm{v}$ mixture of DMAc and acetone, and heated in a flask at $70^{\circ} \mathrm{C}$ for $24 \mathrm{~h}$. After the solution had turned pale yellow, $\mathrm{TiO}_{2}$ NPs were subsequently added to obtain working fluids with NP concentrations of $0,0.5,1.0,1.5$, and $2.0 \mathrm{wt} \%$. The resultant suspension was ultra-sonicated for $4 \mathrm{~h}$. A second solution was prepared by dissolving epoxy resin and the curing agent TETA (total concentration $40 \% \mathrm{w} / \mathrm{v}$; epoxy: TETA ratio $12.6: 1 \mathrm{w} / \mathrm{w})$ in a mixture of acetone and DMAc $(2: 6 \mathrm{v} / \mathrm{v})$, and stirring for $1 \mathrm{~h}$.

After some initial optimization experiments, the $\mathrm{TiO}_{2}-\mathrm{PVDF}$ and epoxy-TETA flow rates were set at 1.3 and $0.35 \mathrm{~mL} / \mathrm{h}$, respectively. The working fluids were dispensed using two syringe pumps (KDS100, Cole-Parmer, USA). An $8 \times 8 \mathrm{~cm}$ square of PET fabric was spread on grounded aluminum foil, and electrospraying performed to coat the fabric. A power supply (ZGF $60 \mathrm{kV} / 2 \mathrm{~mA}$, Shanghai Sute Corp., Shanghai, China) was used to provide a voltage of $12 \mathrm{kV}$, and the distance between the spinneret and collector was $16 \mathrm{~cm}$. The finished fabrics were left to dry at room temperature for at least $72 \mathrm{~h}$.

\subsection{Characterization}


The surface morphology of the fabric before and after modification was observed using a scanning electron microscope (SEM; Quanta FEG450, FEI Corporation, USA) at an accelerating voltage of $20 \mathrm{kV}$. ATR-FTIR spectra were measured with a Tensor 27 spectrometer (IS10 instrument, Nicolet, USA). X-ray diffraction (XRD) was performed using a model number instrument (Karlsruhe, Germany) over the angular range of $10-60^{\circ}$. The wetting properties of the finished fabrics were measured with an contact angle analyser (DSA100, Krüss GmbH Germany). Static contact angle measurements were obtained using an $8 \mu \mathrm{L}$ drop of fluid which was left on the fabric for 30s. Five independent measurements were performed. The mechanical robustness of the finished material $(1 \times 5 \mathrm{~cm})$ was evaluated by determining the contact angle after ultrasonication for various times [71].

\subsection{UV shielding}

UV absorption spectra were obtained on a Lambda 750s UV-vis spectrometer (PerkinElmerUSA). The samples were placed between $30 \mathrm{~mm}$ diameter square frames in the integrating sphere of the instrument and rotated 90 degrees for repeated testing. T(UVA), T(UVB) and the ultraviolet protection factor (UPF) can be calculated using the following equations according to the UPF standard AATCC Test Method 183 [72].

$$
\begin{aligned}
& \mathrm{UPF}=\frac{\sum_{290 \mathrm{~nm}}^{400 \mathrm{~m}} \mathrm{E}_{\lambda} \mathrm{S}_{\lambda} \Delta_{\lambda}}{\sum_{290 \mathrm{~nm}}^{400 \mathrm{~m}} \mathrm{E}_{\lambda} \mathrm{S}_{\lambda} \mathrm{T}_{\lambda} \Delta_{\lambda}} \\
& \mathrm{T}(\mathrm{UVA})=\frac{\sum_{315 \mathrm{~mm}}^{400 \mathrm{~m}} \mathrm{~T}_{\lambda} \Delta_{\lambda}}{\sum_{315 \mathrm{~nm}}^{400 \mathrm{~m}} \Delta_{\lambda}}
\end{aligned}
$$




$$
\mathrm{T}(\mathrm{UVB})=\frac{\sum_{290 \mathrm{~nm}}^{315 \mathrm{~mm}} \mathrm{~T}_{\lambda} \Delta_{\lambda}}{\sum_{290 \mathrm{~mm}}^{315 \mathrm{~mm}} \Delta_{\lambda}}
$$

Where $\mathrm{E}_{\lambda}, \mathrm{S}_{\lambda}, \mathrm{T}_{\lambda}$, and $\Delta_{\lambda}$ are the relative erythemal spectral effectiveness, solar spectral irradiance, the average spectral transmission of the specimen, and the measured wavelength interval $(\mathrm{nm})$, respectively.

\subsection{Determination of antibacterial activity}

To evaluate the antimicrobial activity of the TPE finished fabric the sample was cut into squares of $1 \times 1 \mathrm{~cm}$ and sterilized with $15 \mathrm{~W}$ UV irradiation for 30 minutes. E. coli DH5 $\alpha$ was cultured in LB Broth at $37^{\circ} \mathrm{C}$ (under shaking at $220 \mathrm{rpm}$ ) until the strain reached an OD600 of about 0.6 . The microbial culture $\left(10^{8} \mathrm{CFU} / \mathrm{mL}\right)$ was diluted at a ratio of 1:1000 to a final concentration of $10^{5} \mathrm{CFU} / \mathrm{mL}$. The sterilized test samples were placed into $3 \mathrm{~mL}$ of bacterial solution, with the samples fully immersed. The cultures were then incubated at $37^{\circ} \mathrm{C}$ and $220 \mathrm{rpm}$ in the light, and the OD value determined after $24 \mathrm{~h}$ [73]. Three independent experiments were performed with each fabric sample. The bacterial inhibition rate (\%) was calculated according to the following formula:

$$
\text { Inhibition rate }(\%)=\frac{\mathrm{Blank} \mathrm{OD}_{600}-\text { sample } \mathrm{OD}_{600}}{\mathrm{Blank}_{\mathrm{OD}_{600}}} \times 100 \%
$$

\section{Results and discussion}

\subsection{Nanofinishing using side-by-side electrospraying}


A long-existing challenge in textile functionalization is finding a method to firmly bond the finishing agents (most of which comprise loose powders) to the fabric substrate. Although some reports can be found in the literature encapsulating $\mathrm{TiO}_{2} \mathrm{NPs}_{\mathrm{s}}$ into electrospun nanofibers to endow them with hydrophobic, UV resistant and antibacterial properties [74-76], to date no investigations have sought to bond NPs onto a fabric surface via EHDA. Here we report a new strategy to achieve this based on sideby-side electrospraying (Figure 1). Janus particles have been designed with one side consisting of an adhesive and the other composed of various functional ingredients. The Janus particles developed may be bonded ex-situ onto the surface of fabrics.

Compared to coaxial electrospinning, coaxial electrospraying, and even tri-axial electrospinning, side-by-side EHDA processes are more difficult to implement [77-81]. This is because the standard spinneret used comprises two parallel metal capillaries. When the working fluids exit this spinneret their contact area is very small, and the two fluids have the same charge, causing them to repel one another. To overcome this issue, here we use an acentric spraying head, as reported in the recent literature [82]. The spraying head is shown in the upper-right inset of Figure 1, and ensures a larger contact area between the two working fluids. One side of the spinneret has a crescent shape, while the other is round. This should be beneficial for preventing the separation of the two working fluids and creating integrated Janus structures.

During electrospraying experiments, the epoxy/TETA solution and the $\mathrm{TiO}_{2}-\mathrm{PVDF}$ suspension were respectively pumped from the crescent and round exits of the 
spinneret. Under ambient conditions, the epoxy resin solution is always a liquid, which means that it could not be solidified using electrospraying. Hence, the Janus particles produced comprised one solid $\mathrm{TiO}_{2}-\mathrm{PVDF}$ side for functional performance, and a liquid epoxy resin side for bonding on the fabric surface.

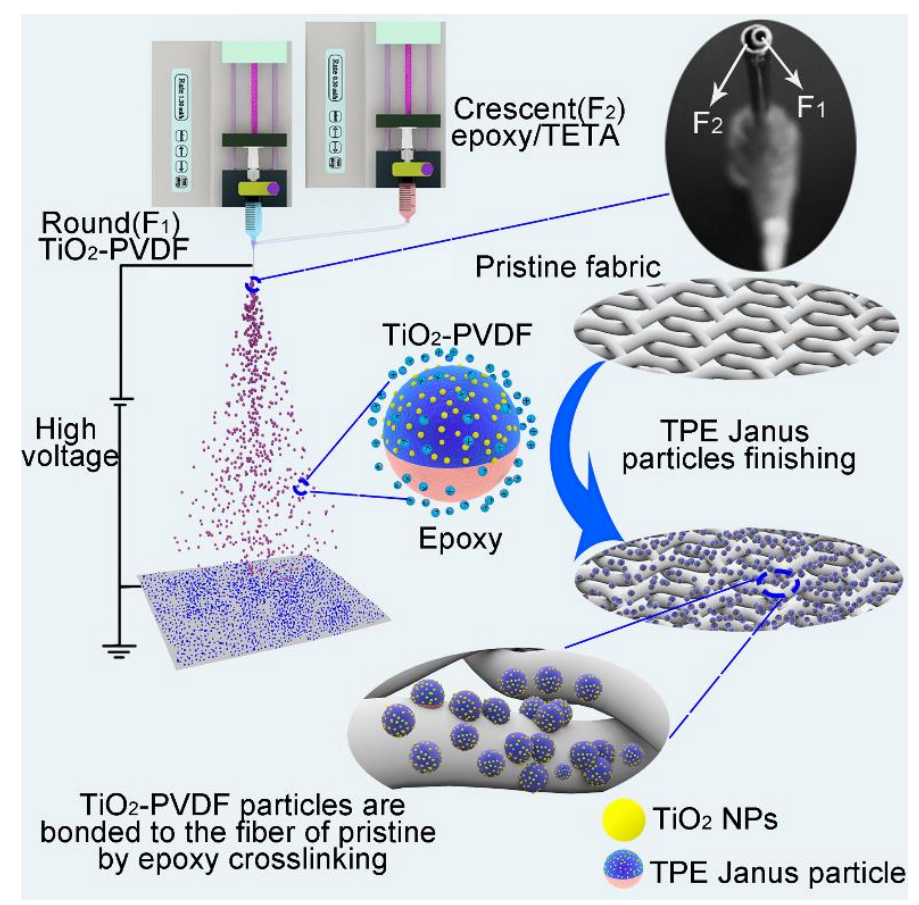

Figure 1. Textile nano finishing using side-by-side electrospraying. The upper-right inset shows a digital photograph of the acentric spraying head.

During the electrospraying process (Figure S1a and S1b, Supporting Information), a side-by-side compound Taylor cone was observed under the optimized processing conditions (Figure 2a). The white side of the cone comprises the $\mathrm{TiO}_{2}-\mathrm{PVDF}$ suspension, while the transparent side is the epoxy solution. After the Taylor cone, a straight fluid jet and an atomization region were observed (Figure S1b, Supporting Information). In the atomization region, the Coulombic explosion causes the droplets 
to split rapidly; at the same time the solvent evaporates and solid material is deposited on the collector $[83,84]$.

For a monoaxial or coaxial electrospraying process, the droplet splitting process is generally straightforward and results in only a single type of product. However, in the side-by-side process, the situation is more complicated because droplet splitting could happen at both the adjacent fluids. There at least two possible splitting processes that could arise (Figure 2b). These include simultaneous splitting of both fluids within a droplet, resulting in the shrinkage and solidification of the droplet to form Janus particles with a $\mathrm{TiO}_{2}-\mathrm{PVDF}$ solid side and an epoxy slurry side (TPE particles).

Here, the $\mathrm{TiO}_{2}$-PVDF particles will be firmly bonded to the fabric thanks to the curing of the epoxy resin. However, under ambient conditions, the epoxy resin was in a liquid slurry state. The evaporation rates of the solvents in the epoxy resin and PVDF sides will be different. Thus, it is possible that the PVDF fluid within the Janus droplets will dry to an extent that it could not split any further, while the epoxy side could still split into smaller droplets. Under this situation, some tiny epoxy droplets would separate from the Janus droplets. This is expected to have minimal influence on the finishing, however. 


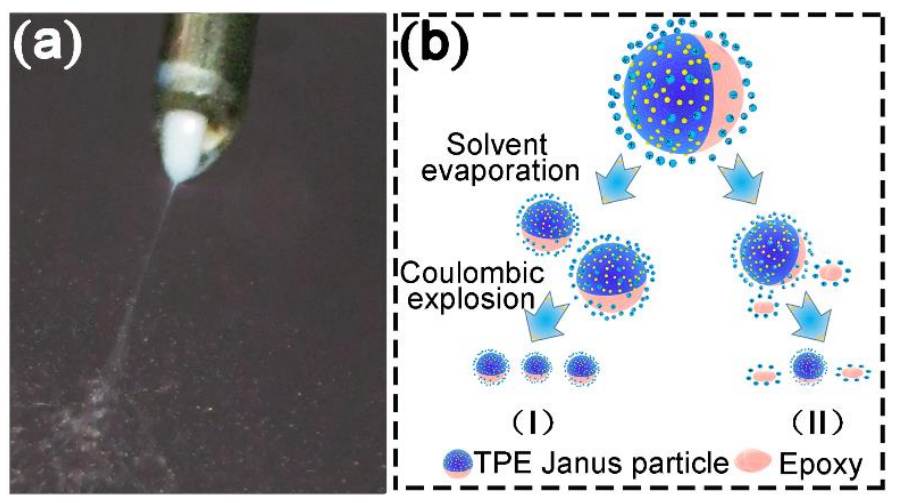

Figure 2. The side-by-side electrospraying process: (a) a digital picture of the compound Taylor cone; (b) a diagram showing the routes by which the charged droplets could split during atomization.

\subsection{Morphology and nanostructure}

As shown in Figure $3 \mathrm{a}$, the pristine fabric comprised relatively smooth fibers arranged in a regular fashion. The fact that water droplets can spread between the fibers, and the hollow space between them, results in the pure fabric being highly hydrophilic [85]. A water droplet applied to the surface rapidly spreads and disappears into the fabric, giving a contact angle (CA) of $0^{\circ}$ (Figure $3 \mathrm{a}$, inset). After electrospraying, the fabric fibers can be seen to be coated with microparticles (Figure 3b), with varied deposition density. The CA value increases to $152^{\circ}$ on the fabric finished with TPE Janus particles (Figure 3b, inset). Water droplets were retained on the surface of the fabric decorated by TPE particles. The hydrophobic nature of PVDF, the presence of the $\mathrm{TiO}_{2}$ nanoparticles, the cross-linked epoxy resin, and probably also the air at the solid-liquid interface, all act together to block the water droplets from penetrating into the fabric. 
When the particles were deposited on the fabric, they appear to be bonded to the surfaces of the fibers comprising the fabric (see Figure 3c, blue highlighting), largely as a result of the presence of the epoxy resin (Figure S1c and S1d, Supporting Information). This arises because of the curing of the resin in the presence of TETA (Figure S2, Supporting Information). The TPE particles tend to pile up on the exterior of the fabric (Figure 3d). Energy-dispersive X-ray spectroscopy (EDX) data (Figure 3e) confirm the presence of $\mathrm{Ti}$ in the electrosprayed particles, which are found to have diameters of $3.19 \pm 0.94 \mu \mathrm{m}$ (Figure 3f). The TPE Janus particles are deposited only on one side of the fabric, which will result this having superhydrophobic properties. The non-coated side will retain the initial hydrophilic properties and the softness of the pristine fabric, which is desired for commercial applications [86].
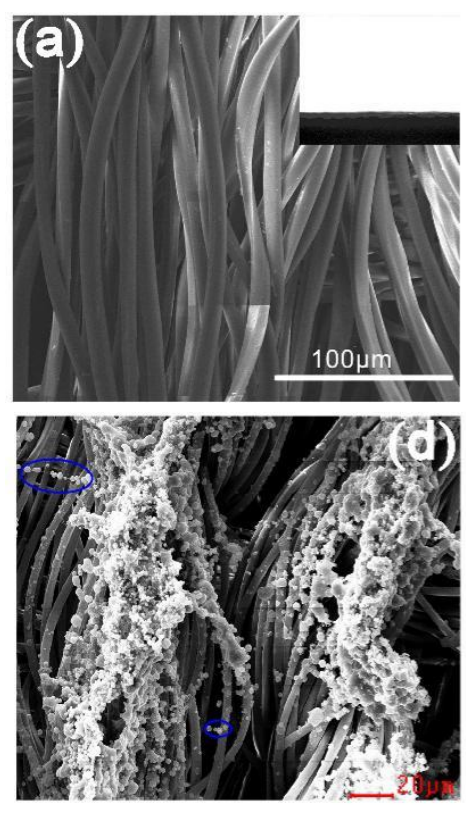
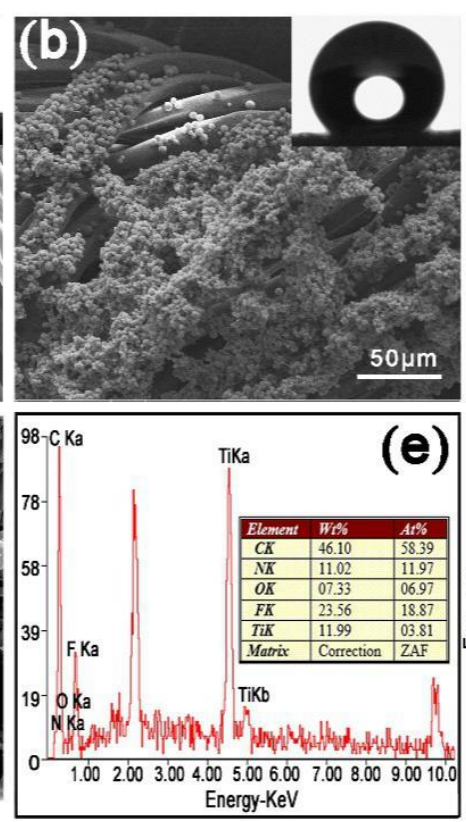
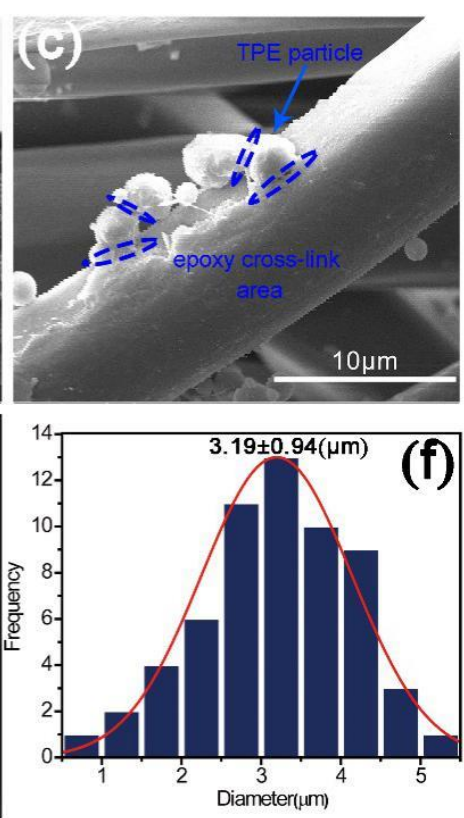

Figure 3. SEM images of (a) the pristine fabric and (b-d) after finishing with TPE particles containing $\mathrm{TiO}_{2}$ concentrations of $2 \mathrm{wt} \%$, with the corresponding EDX 
spectrum (e) and diameter distribution (f). The insets in (a) and (b) show photographs of a droplet of water placed on the surface.

\subsection{Physical form and component compatibility}

X-ray diffraction (XRD) patterns of the $\mathrm{TiO}_{2}$ NPs and Janus particles prepared both with and without $\mathrm{TiO}_{2}$ are given in Figure 4a. The $\mathrm{TiO}_{2}$ NPs are seen to comprise a mixture of the anatase and rutile polymorphs. Electrosprayed Janus particles prepared without the addition of $\mathrm{TiO}_{2}$ exhibited broad peaks at $2 \theta$ of $19.78^{\circ}$ and $20.48^{\circ}$, which originate from the $\beta$ phase of PVDF [87]. A weak reflection at ca. $18.4^{\circ} \mathrm{can}$ be attributed to the (020) reflection of the $\alpha$ PVDF phase. These PVDF reflections can still be discerned when $\mathrm{TiO}_{2}$ NPs are incorporated into the particles, albeit with some small shifts in position [88]. In both cases, the $\beta$ phase of PVDF dominates. This occurs because during the electrospraying processes the PVDF molecules reorient themselves under the influence of the electrical field, which promotes the formation of the polar $\beta$ phase over the non-polar $\alpha$ system. Distinctive Bragg reflections of both rutile and anatase $\mathrm{TiO}_{2}$ can also be observed in the pattern of the loaded particles.

(a)

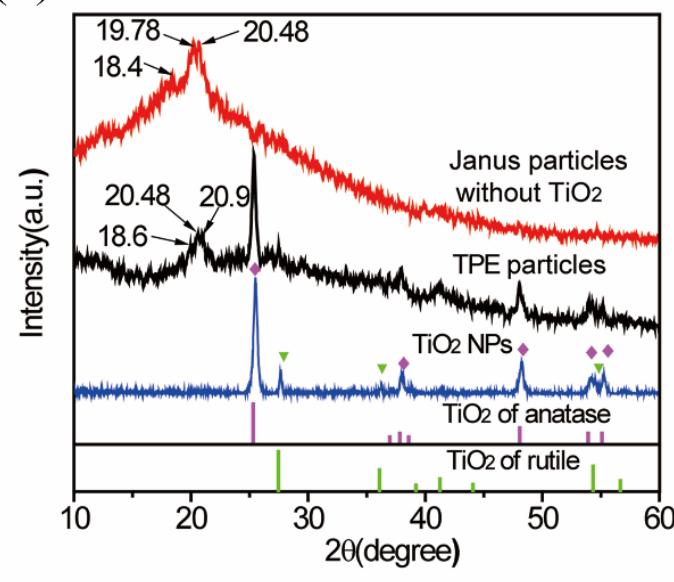

(b)

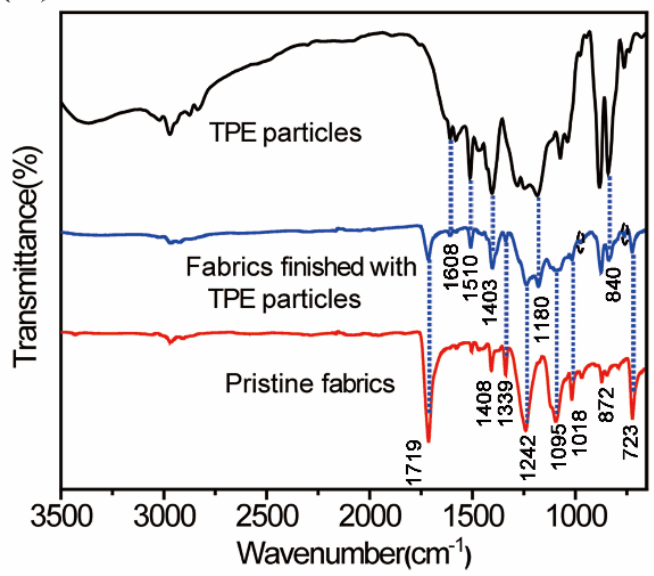


Figure 4. (a) XRD patterns of $\mathrm{TiO}_{2}$ and Janus particles. (b) FTIR spectra of the pristine fabric, TPE particles, and the finished fabric.

FTIR spectra are shown in Figure 4b. In the FTIR spectrum of fabric finished with the TPE particles, characteristic absorbance peaks at $763 \mathrm{~cm}^{-1}\left(\mathrm{CF}_{2}\right.$ bending and skeletal bending) and $975 \mathrm{~cm}^{-1}\left(\mathrm{CH}_{2}\right.$ rocking) are attributed to $\alpha$-phase PVDF [89]. A small absorbance band at $840 \mathrm{~cm}^{-1}\left(\mathrm{CH}_{2}\right.$ rocking and $\mathrm{CF}_{2}$ stretching $)$ is a signature of the $\beta$-phase $[88,90]$. Distinctive peaks at $1180 \mathrm{~cm}^{-1}$ and $1403 \mathrm{~cm}^{-1}$ correspond to stretching and deformation vibrations of $\mathrm{C}-\mathrm{F}$ bonds [91, 92]. Characteristic aromatic peaks from the epoxy resin can be seen at 1510 and $1608 \mathrm{~cm}^{-1}$ in the spectrum of the finished fabric. The pristine fabric shows absorption bands at 872 and $1408 \mathrm{~cm}^{-1}$ which are absent in the finished material. This, together with the weakening of other distinct absorbance peaks from the fabric (at $723,1095,1242,1719,1339 \mathrm{~cm}^{-1}$ ) is ascribed to coverage of the TPE particles on the fabric surface (Table S1, Supporting Information). Figure S3 displays the FTIR spectra of fabric finished with TPE particles both before and after $72 \mathrm{~h}$ of curing. Bands at $600 \mathrm{~cm}^{-1}$ (Ti-O stretching) can be seen, and the peak at $3022 \mathrm{~cm}^{-1}$ belongs to the stretching vibration of the hydroxyl group $\mathrm{O}-\mathrm{H}$ of the $\mathrm{TiO}_{2}$ [93]. In neither spectrum can the epoxy groups be seen, indicating that the 0 epoxy groups of undergo a ring-opening curing reaction in a very short time.

\subsection{Optical properties}

To optimize the optical properties, fabrics were finished with TPE particles containing a range of concentrations of $\mathrm{TiO}_{2}$. SEM images and EDX spectra of these 
are shown in Figure S4 and S5 of the Supporting Information. The optical absorption spectra of the pristine and finished fabrics were measured using a UV-Vis spectrometer over the wavelength range of $200 \sim 400 \mathrm{~nm}$. The wavelength of ultraviolet radiation wad divided into three categories: UVA (320-400 nm), UVB (280-400 nm) and UVC (200$280 \mathrm{~nm}$ ) [94]. UVC, which leads to the greatest skin damage, is almost completely blocked by the ozone layer, so the UV protection was primarily aimed at UVA and UVB. It is clear from Figure 5a that the greater the content of $\mathrm{TiO}_{2} \mathrm{NPs}$ in the TPE particles, the greater the absorption of UV light by the finished fabrics. There is strong UV absorption intensity appearing over the UVB wavelength range.

(a)

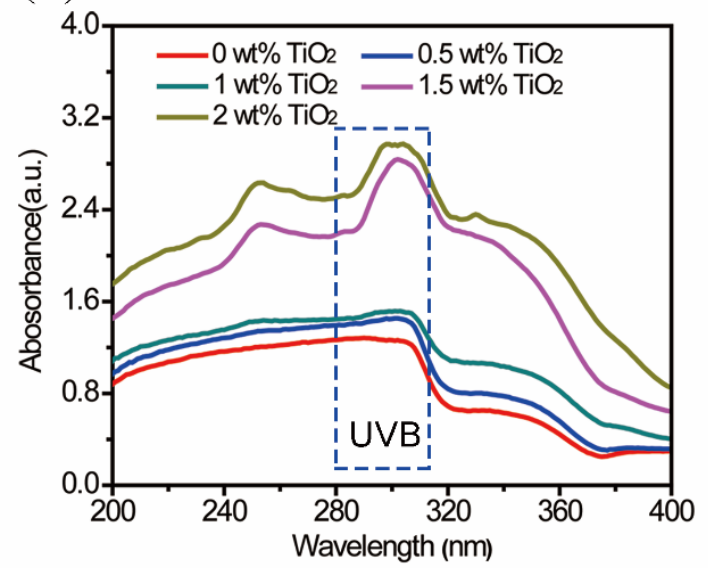

(b)

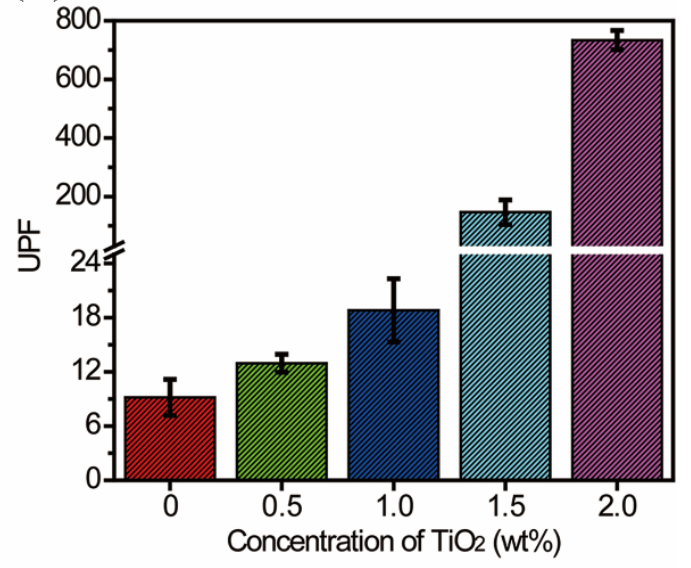

Figure 5. The UV absorbance of fabrics finished with TPE particles containing varied concentrations of $\mathrm{TiO}_{2} \mathrm{NP}$ : (a) UV absorption spectra, (b) UPF values.

The ultraviolet protection factor (UPF) values were used to calculate the resistance to ultraviolet radiation, as shown in Figure 5b. The fabrics finished with TPE particles without $\mathrm{TiO}_{2}$ had a UPF of 9.17, indicating that UV shielding was poor. The introduction of $\mathrm{TiO}_{2}$ into the TPE particles causes the UPF values to increase, reaching 
733 at $2.0 \mathrm{wt} \%$. This is attributed to the UV-absorbing capabilities of $\mathrm{TiO}_{2}$. Under the electrospraying conditions, a higher concentration of $\mathrm{TiO}_{2}$ in the PVDF side fluid led to more $\mathrm{TiO}_{2}$ NPs being distributed on the surface of the fabric. Hence, the number of active sites that can absorb ultraviolet light on the surface of the fabric increase correspondingly, engendering a successive increase of ultraviolet absorption intensity and the UPF value. According to GB/T 18830-2009 if the UPF value of a material is $>$ 40 and $\mathrm{T}(\mathrm{UVA})<5 \%$ it can be referred to as a "UV protection product'. In this study, when the PVDF side fluid contained a concentration of $2.0 \mathrm{wt} \% \mathrm{TiO} 2 \mathrm{NPs}$ the finished fabric had a UPF value of 733 and T (UVA) of 3.08\%, meeting this standard (Table S2, Supporting Information).

\subsection{Wettability and Permeability}

The pristine fabric has a strong tendency to absorb moisture (Movie S1, Supporting Information), which is related to the presence of hydroxyl groups on the surface of the fibers and the capillary effect caused by the voids between fibers. The water contact angle (CA) of fabric finished with TPE particles containing no $\mathrm{TiO}_{2}$ was $134^{\circ}$. The introduction of TPE particles thus enhances the hydrophobicity of the finished fabric. With an increase in $\mathrm{TiO}_{2}$ concentration, the $\mathrm{CA}$ values of the finished fabrics increase further, reaching $138^{\circ}, 143.5^{\circ}, 150.5^{\circ}$, and $152^{\circ}$ for TPE particles prepared with PVDF fluids containing 0.5, 1.0, 1.5 and $2.0 \mathrm{wt} \% \mathrm{TiO}_{2}$ (Figure 6a). A hierarchical and rough hydrophobic layer on the fabric surface is formed by the finishing process $[18,95]$, arising through the agglomeration of TPE particles due to in situ bonding by the epoxy 
resin (Figure 6b) [96]. These hydrophobic nature of the components in the TPE particles additionally endowed the finished fabrics with the ability to repel liquids such as ink, coffee, and milk. A digital photo demonstrating this is shown in Figure 6c. The liquid droplets all maintain a spherical shape on the finished fabric and do not absorb into it.

The fabrics finished with TPE Janus particles had excellent self-cleaning performance, demonstrated in Figure $6 \mathrm{~d}$. When dyed water droplets are placed on the surface of the finished fabric covered with chalk powder, they gather together and remove the solid contaminants. Water can clearly slide over the fabric surface without wetting it (Movie S2, Supporting Information). In Figure 6e, a water droplet of $8 \mu \mathrm{L}$ on a syringe needle is seen to retain its spherical shape when placed on the finished fabric. Further, when the syringe is moved over the surface, the droplet can be fully detached from the fabric surface even after repeated contacts (see also Movie S3, Supporting Information). These phenomena demonstrate that the fabric has excellent anti-adhesion properties after finishing with the TPE particles, expected to be a result of the low surface energy of the hierarchical surface structure post-finishing [97, 98].

SEM images of the fabrics finished with TPE Janus particles suggest that there are still many pores in them (see Figure 6f, left). These have diameters larger than $110 \mu \mathrm{m}$ and should permit the fabric to retain gas permeability properties. To test this, a beaker containing boiling water was sealed with the finished fabric (Figure $6 f$, right). Water vapor could be clearly seen above the beaker, confirming that the TPE particle functionalization does not hamper gas transfer and breathability. 
We also explored the durability of the finished fabric. A sample immersed in alcohol was treated over one hour under ultrasonic vibration, and the CA measured. The CA value declines slightly in the first $15 \mathrm{~min}$, but then remained at $140^{\circ}$ for the remainder of the treatment time (Figure S6, Supporting Information), confirming that the coating is robustly applied and remains in place.

(a)

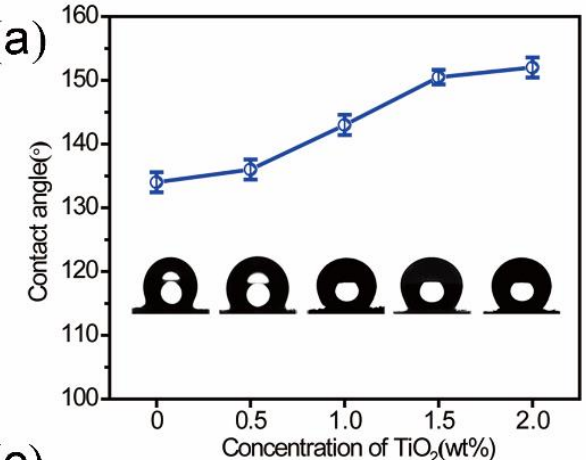

(c)

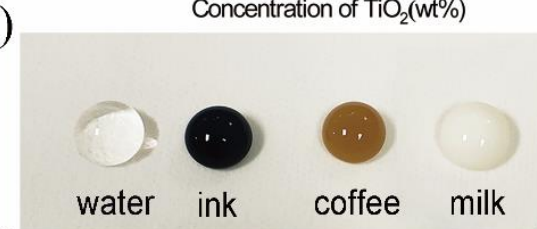

(d) water ink coffee milk

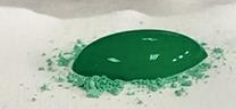

(e)

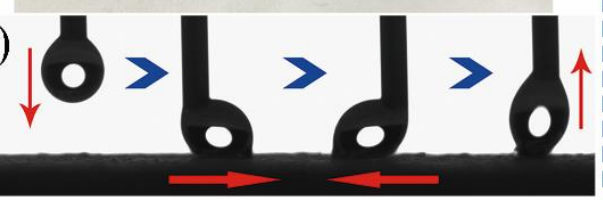

(b)

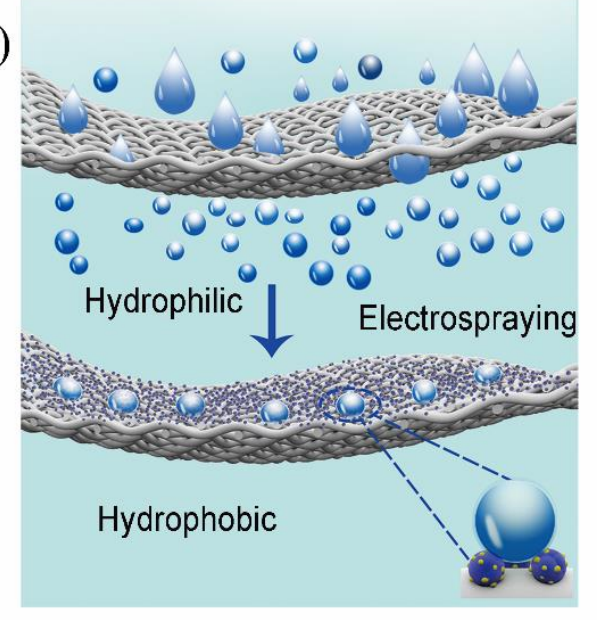

(f)

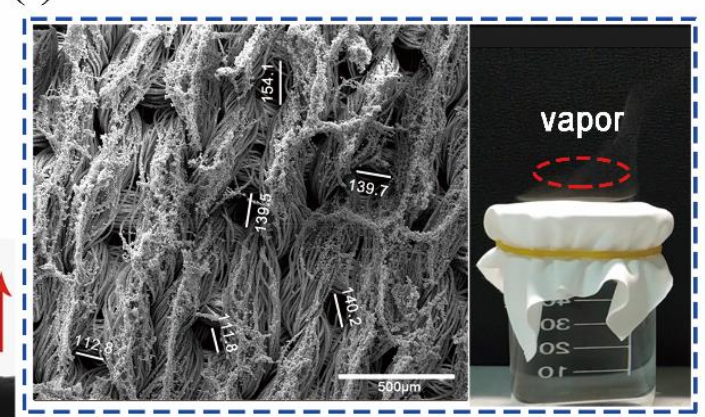

Figure 6. Wettability and permeability of fabric finished with TPE particles: (a) The change in $\mathrm{CA}$ with $\mathrm{TiO}_{2}$ concentration. (b) A schematic illustrating the behavior when water droplets were are on the surface of the pristine and finished fabric. (c) Water repellent, (d) self-cleaning, (e) anti-adhesion properties and (f) breathability of the 
fabric finished with TPE Janus particles containing $2 \mathrm{wt} \% \mathrm{TiO}_{2}$ (left: an SEM image; right a digital image showing the transmission of vapor).

\subsection{Antimicrobial Activity}

The finished fabrics could produce antibacterial effects through two potential mechanisms (Figure 7a) $[99,100]$. (I) When a bacterial suspension comes into contact with the surface of the fabric, the bacteria will encounter the TPE Janus particles, which can kill them and prevent proliferation. (II) The hydrophobic nature of the fiber surface after finishing ensures that the bacteria are kept at the surface and cannot enter the bulk of the fabric.

Bacterial growth kinetics were quantified to assess the antimicrobial activity of the finished fabric. $\mathrm{TiO}_{2}$ has antibacterial properties which are induced by UV-treatment, as shown in Figure 7b. Conduction band electrons and valence band holes are generated by UV induction. These photogenerated electrons and holes undergo a series of reactions with oxygen and water respectively, which further form reactive oxygen species (ROS) such as ${ }^{\circ} \mathrm{OH}, \mathrm{O}_{2}{ }^{\circ}, \mathrm{H}_{2} \mathrm{O}_{2}[101,102]$. These ROS cause the oxidation of cellular components and membrane leakage. The maximum optical density (OD) observed with the untreated fabric after immersion in LB broth for E. coli DH5 $\alpha$ was $0.924 \pm 0.024$. No inhibition of E. coli growth was observed after $24 \mathrm{~h}$ with a fabric finished with $0.5 \mathrm{wt} \% \mathrm{TiO}_{2} \mathrm{NPs}$. However, the bacterial inhibition rate increases with the $\mathrm{TiO}_{2}$ content (Figure 7c) [103]. The lowest maximum OD was observed, indicating fabrics finished with TPE Janus particles containing $\mathrm{TiO}_{2}$ NPs have significant 
antibacterial ability against E. coli DH5 . The fabric finished with particles from a 2 $\mathrm{wt} \% \mathrm{TiO}_{2}$ NPs suspension was able to inactivate $74.8 \%$ of the bacterial colonies in 24 $\mathrm{h}[104,105]$.

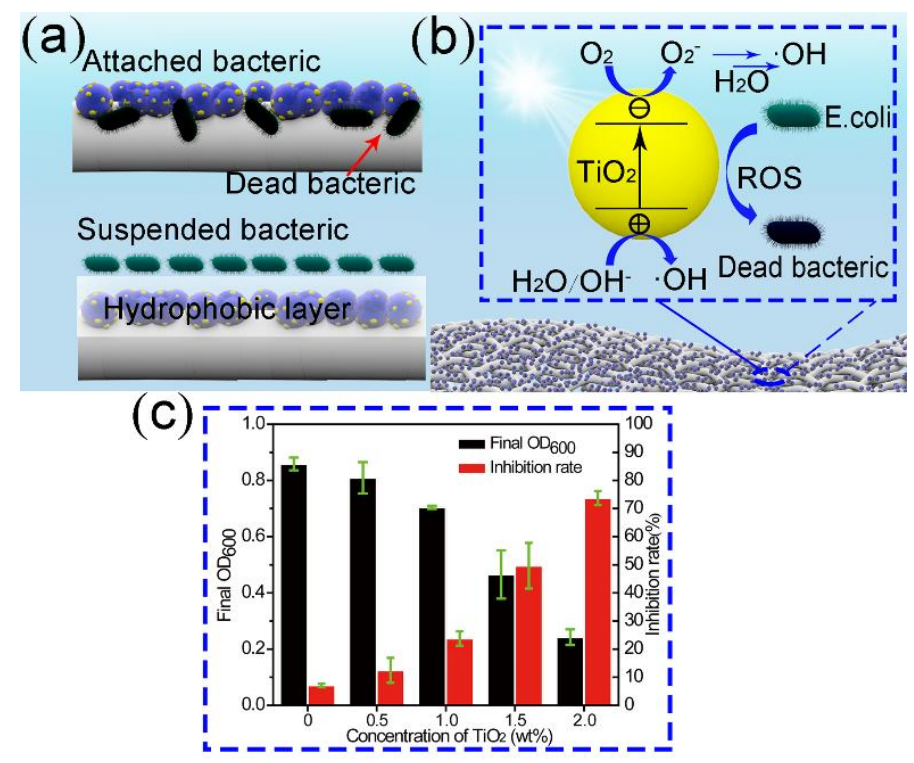

Figure 7. Antibacterial performance of fabrics finished with TPE Janus particles. (a) The mechanisms underlying the antibacterial action model of the finished fabrics. (b) A schematic illustration of the antibacterial effect arising through $\mathrm{TiO}_{2}$ photocatalysis. (c) $\mathrm{OD}_{600}$ values and inhibition rates against E. coli DH5 $\alpha$.

In the present study, the multifunctionality of the finished fabrics originates from the PVDF-TiO 2 side of the Janus particles. The epoxy resin side of the particles also had an important role, ensuring the binding of the functional ingredients PVDF and $\mathrm{TiO}_{2}$ to the surface of the fabric. The two sides acted together to ensure a successful nano-finishing process. Given this proof-of-concept demonstration, a wide variety of potential applications can be envisaged. On one hand, a wide variety of inorganic NPs and even inorganic nanotubes $[106,107]$ can be easily finished onto the fabric surface 
to develop functional textiles. Further, the successful usage of a unsolidifiable solution as a side working fluid in this work should promote further investigation into the fundamental engineering principles of EHDA. The two-fluid side-by-side electrospraying pioneered here can be further developed into three-fluid EHDA processes (such as tri-axial, tri-layer side-by-side, or combinations of coaxial and sideby-side) for functionalizing fabrics with multifunctional particles with more complicated structures.

\section{Conclusions}

Here we report a simple strategy for finishing fabrics based on side-by-side electrospraying. The use of a liquid binder (epoxy resin) as one side of the Janus particles that result from electrospraying allowed them to effectively bind to the fibers which make up a fabric substrate. The other side of the particles contained PVDF, a hydrophobic polymer, and $\mathrm{TiO}_{2} \mathrm{NPs}$. The coating was observed to result in an irregular hierarchical coating. Fabrics finished with the Janus particles were demonstrated to have UPF values up to 733, suggesting potent UV protection properties. The optimum finished fabric had a water contact angle of $152^{\circ}$ and was found to be extremely hydrophobic. This renders it able to resist staining, and also endows it with self-cleaning properties. The finished fabric was able to inactivate $74.8 \%$ of E. coli DH5 $\alpha$ bacterial colonies in 24 hours. 


\section{Acknowledgments}

This work was financially supported by the National Natural Science Foundation of China (No. 5130701) and the Shanghai Natural Science Foundation (No. 20ZR1439000).

\section{Appendix A. Supporting Information}

The following files are available free of charge.

\section{References}

[1] J. He, W. Wang, F. Sun, W. Shi, D. Qi, K. Wang, R. Shi, F. Cui, C. Wang, X. Chen, Highly efficient phosphate scavenger based on well-dispersed $\mathrm{La}(\mathrm{OH})_{3}$ nanorods in polyacrylonitrile nanofibers for nutrient-starvation antibacteria, ACS Nano 9 (2015) 9292-9302, https://doi.org/10.1021/acsnano.5b04236.

[2] J. Zhu, L. Yuan, Q. Guan, G. Liang, A. Gu, A novel strategy of fabricating high performance UV-resistant aramid fibers with simultaneously improved surface activity, thermal and mechanical properties through building polydopamine and graphene oxide bi-layer coatings, Chem. Eng. J. 310 (2017) 134-147, https://doi.org/10.1016/j.cej.2016.10.099.

[3] K.-A. Johnson, N. Muzzin, S. Toufanian, R.A. Slick, M.W. Lawlor, B. Seifried, P. Moquin, D. Latulippe, T. Hoare, Drug-impregnated, pressurized gas expanded liquid-processed alginate hydrogel scaffolds for accelerated burn wound healing, Acta Biomater. 112 (2020) 101-111, https://doi.org/10.1016/j.actbio.2020.06.006.

[4] B. Jalvo, M. Faraldos, A. Bahamonde, R. Rosal, Antibacterial surfaces prepared by electrospray coating of photocatalytic nanoparticles, Chem. Eng. J. 334 (2018) 1108-1118, https://doi.org/10.1016/j.cej.2017.11.057.

[5] Q. Qiu, S. Chen, Y. Li, Y. Yang, H. Zhang, Z. Quan, X. Qin, R. Wang, J. Yu, Functional nanofibers embedded into textiles for durable ntibacterial properties, Chem. Eng. J. 384 (2020) 123241, https://doi.org/10.1016/j.cej.2019.123241.

[6] Y. Deng, D. Han, Y.-Y. Deng, Q. Zhang, F. Chen, Q. Fu, Facile one-step preparation of robust hydrophobic cotton fabrics by covalent bonding polyhedral oligomeric silsesquioxane for ultrafast oil/water separation, Chem. Eng. J. $379 \quad$ (2020) 122391, https://doi.org/10.1016/j.cej.2019.122391.

[7] N. A. Ibrahim, A. Amr, B. M. Eid, Multipurpose treatment of cellulose-containing fabrics to impart durable antibacterial and repellent properties, Fiber. Polym. 21 (2020) 513-521, 
https://doi.org/10.1007/s12221-020-9221-4.

[8] N. A. Ibrahim, A. A. Aly, B. M. Eid, H. M. Fahmy, Green approach for multifunctionalization of cellulose-containing fabrics, Fiber. Polym. 19 (2018) 2298-2306, https://doi.org/10.1007/s12221-018-8602-4.

[9] N. A. Ibrahim, Basma M. Eid, E. A. El-Aziz, T. M. Abou Elmaaty, S. M. Ramadan, Multifunctional cellulose-containing fabrics using modified finishing formulations, RSC Adv. 7 (2017) 33219-33230, https://doi.org/10.1039/C7RA05403C.

[10] N. A. Ibrahim, E. M. El-Zairy, B. M. Eid, E. Emam, S. R. Barkat, A new approach for imparting durable multifunctional properties to linen-containing fabrics, Carbohydr. Polym. 157 (2017) 1085-1093, https://doi.org/10.1016/j.carbpol.2016.10.074.

[11] A. Ibrahim, B. M. Eid, M. A. Youssef, H. A. Ameen, A. M. Salah, Surface modification and smart functionalization of polyester-containing fabrics, J. Ind. Text. 42 (2012) 353-375, https://doi.org/10.1177/1528083712440899.

[12] Agrawal, J. S. J. Tan, P. S. Low, E. W. M. Fong, Y. Lai, Z. Chen, Green synthesis of robust superhydrophobic antibacterial and UV-blocking cotton fabrics by a dual-stage silanization approach, Adv. Mater. Interfaces 6 (2019) 1900032, https://doi.org/10.1002/admi.201900032.

[13] Y. Shen, X. Wu, J. Tao, C. Zhu, Y. Lai, Z. Chen, Icephobic materials: Fundamentals, performance evaluation, and applications, Prog. Mater. Sci. 103 (2019) 509-557, https://doi.org/10.1016/j.pmatsci.2019.03.004.

[14] H. Liu, Y. Wang, J. Huang, Z. Chen, G. Chen, Y. Lai, Bioinspired surfaces with superamphiphobic properties: Concepts, synthesis, and applications, Adv. Funct. Mater. 28 (2018) 1707415, https://doi.org/10.1002/adfm.201707415.

[15] E.-J. Lee, B.J. Deka, A.K. An, Reinforced superhydrophobic membrane coated with aerogelssisted polymeric microspheres for membrane distillation, J. Membr. Sci. 573 (2019) 570-578, https://doi.org/10.1016/j.memsci.2018.12.019.

[16] B. Deka, E.-J. Lee, J. Guo, J. Kharraz, A.K. An, Electrospun nanofiber membranes incorporating pdms-aerogel superhydrophobic coating with enhanced flux and improved antiwettability in membrane distillation, Environ. Sci. Technol. 53 (2019) 4948-4958, https://doi.org/10.1021/acs.est.8b07254.

[17] W. Jia, J.A. Kharraz, P.J. Choi, J. Guo, B.J. Deka, A.K. An, Superhydrophobic membrane by hierarchically structured PDMS-POSS electrospray coating with cauliflower-shaped beads for enhanced MD performance, J. Membr. Sci. 597 (2020) 117638, https://doi.org/10.1016/j.memsci.2019.117638.

[18] Y.H. Liu, L. Moevius, X.P. Xu, T.Z. Qian, J.M. Yeomans, Z.K. Wang, Pancake bouncing on superhydrophobic surfaces, Nat. Phys. 10 (2014) 515-519, https://doi.org/10.1038/nphys2980. 
[19] R.N. Wenzel, Resistance of solid surfaces to wetting by water, Ind. Eng. Chem. 28 (1936) 988994, https://doi.org/10.1021/ie50320a024.

[20] L. Gustafsson, R. Jansson, M. Hedhammar, W. Van der wijngaart, Structuring of functional spider silk wires, coatings, and sheets by self-assembly on superhydrophobic pillar surfaces, Adv. Mater. 30 (2018) 1704325, https://doi.org/10.1002/adma.201704325.

[21] M.M. Xiong, Z.H. Ren, W.J. Liu, Fabrication of uv-resistant and superhydrophobic surface on cotton fabric by functionalized polyethyleneimine/ $/ \mathrm{SiO}_{2}$ via layer-by-layer assembly and dipcoating, Cellulose 26 (2019) 8951-8962, https://doi.org/10.1007/s10570-019-02705-5.

[22] X.Y. Zhou, Z.Z. Zhang, X.H. Xu, F. Guo, X.T. Zhu, X.H. Men, B. Ge, Robust and durable superhydrophobic cotton fabrics for oil/water separation, ACS Appl. Mater. Interfaces 5 (2013) 7208-7214, https://doi.org/10.1021/am4015346.

[23] Y. Cheng, T.X. Zhu, S.H. Li, J.Y. Huang, J.J. Mao, H. Yang, S.W. Gao, Z. Chen, Y.K. Lai, A novel strategy for fabricating robust superhydrophobic fabrics by environmentally-friendly enzyme etching, Chem. Eng. J. 355 (2019) 290-298, https://doi.org/10.1016/j.cej.2018.08.113.

[24] Y. Cheng, T. Zhu, S. Li, J. Huang, J. Mao, H. Yang, S. Gao, Z. Chen, Y. Lai, A novel strategy for fabricating robust superhydrophobic fabrics by environmentally-friendly enzyme etching, Chem. Eng. J. 355 (2019) 290-298, https://doi.org/10.1016/j.cej.2018.08.113.

[25] N. A. Ibrahim, B. M. Eid, M. S. Abdel-Aziz, Effect of plasma superficial treatments on antibacterial functionalization and coloration of cellulosic fabrics, Appl. Surf. Sci. 392 (2017) 1126-1133, https://doi.org/10.1016/j.apsusc.2016.09.141.

[26] M. S. Abdel-Aziz, B. M. Eid, N. A. Ibrahim, Biosynthesized silver nanoparticles for antibacterial treatment of cellulosic fabrics using $\mathrm{O}_{2}$-plasma, AATCC J. Res. 1 (2014) 6-12, https://doi.org/10.14504/ajr.1.1.2.

[27] M. Kooti, S. Gharineh, M. Mehrkhah, A. Shaker, H. Motamedi, Preparation and antibacterial activity of $\mathrm{CoFe}_{2} \mathrm{O}_{4} / \mathrm{SiO}_{2} / \mathrm{Ag}$ composite impregnated with streptomycin, Chem. Eng. J. 259 (2015) 34-42, https://doi.org/10.1016/j.cej.2014.07.139.

[28] N. A. Ibrahim, B. M. Eid, E. A. El-Aziz, T. M. A. Elmaaty, S. M. Ramadan, Loading of chitosan-nano metal oxide hybrids onto cotton/polyester fabrics to impart permanent and effective multifunctions, Int. J. Biol. Macromol. 105 (2017) 769-776, https://doi.org/10.1016/j.ijbiomac.2017.07.099.

[29] Y. Tang, H. Sun, Z. Qin, S. Yin, L. Tian, Z. Liu, Bioinspired photocatalytic ZnO/Au nanopillarmodified surface for enhanced antibacterial and antiadhesive property, Chem. Eng. J. 398 (2020) 125575, https://doi.org/10.1016/j.cej.2020.125575.

[30] Z. Sun, T. Liao, K. Liu, L. Jiang, J. H. Kim, S. X. Dou, Robust superhydrophobicity of hierarchical $\mathrm{ZnO}$ hollow microspheres fabricated by two-step self-assembly, Nano Res. 6 (2013) 726-735, https://doi.org/10.1007/s12274-013-0350-6. 
[31] Z. Sun, T. Liao, W. Li, Y. Dou, K. Liu, L. Jiang, S.-W. Kim, J. Ho Kim, S. Xue Dou, Fishscale bio-inspired multifunctional ZnO nanostructures, NPG Asia Mater. 7 (2015) e232-e232, https://doi.org/10.1038/am.2015.133.

[32] N. A. Ibrahim, A. A. Nada, A. G. Hassabo, B. M. Eid, A. M. Noor El-Deen, N. Y. Abou-Zeid, Effect of different capping agents on physicochemical and antimicrobial properties of $\mathrm{ZnO}$ nanoparticles, Chem. Pap. 71 (2017) 1365-1375, https://doi.org/10.1007/s11696-017-0132-9.

[33] Y. Xu, J. Ma, Y. Han, H. Xu, Y. Wang, D. Qi, W. Wang, A simple and universal strategy to deposit $\mathrm{Ag} /$ polypyrrole on various substrates for enhanced interfacial solar evaporation and

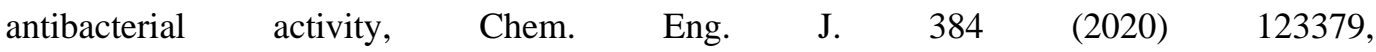
https://doi.org/10.1016/j.cej.2019.123379.

[34] C. Shuai, W. Guo, P. Wu, W. Yang, S. Hu, Y. Xia, P. Feng, A graphene oxide-Ag co-dispersing nanosystem: Dual synergistic effects on antibacterial activities and mechanical properties of $\begin{array}{llllll}\text { polymer scaffolds, } & \text { Chem. } & \text { Eng. J. } 347 & \text { (2018) 322-333, }\end{array}$ https://doi.org/10.1016/j.cej.2018.04.092.

[35] C. Liu, H. Shan, X. Chen, Y. Si, X. Yin, J. Yu, B. Ding, Novel inorganic-based n-halamine nanofibrous membranes as highly effective antibacterial agent for water disinfection, ACS Appl. Mater. Interfaces 10 (2018) 44209-44215, https://doi.org/10.1021/acsami.8b18322.

[36] N. A. Ibrahim, Chapter 12-nanomaterials for antibacterial textiles, In Nanotechnology in diagnosis, treatment and prophylaxis of infectious diseases, Rai, M., Kon, K., Eds. Academic Press: Boston (2015) pp 191-216, https://doi.org/10.1016/B978-0-12-801317-5.00012-8.

[37] X. Zhang, M. Ge, J. Dong, J. Huang, J. He, Y. Lai, Polydopamine-inspired design and synthesis of visible-light-driven Ag NPs@C@elongated $\mathrm{TiO}_{2}$ NTs core-shell nanocomposites for sustainable hydrogen generation, ACS Sustain. Chem. Eng. 7 (2019) 558-568, https://doi.org/10.1021/acssuschemeng.8b04088.

[38] L. Zhang, S. Yang, Y. Lai, H. Liu, Y. Fan, C. Liu, H. Wang, L. Chai, In-situ synthesis of monodispersed $\mathrm{Cu}_{x} \mathrm{O}$ heterostructure on porous carbon monolith for exceptional removal of gaseous $\mathrm{Hg}^{0}, \quad$ Appl. Catal. B-Environ. 265 (2020) 118556, https://doi.org/10.1016/j.apcatb.2019.118556.

[39] J. Dong, J. Huang, A. Wang, G. V. Biesold-McGee, X. Zhang, S. Gao, S. Wang, Y. Lai, Z. Lin, Vertically-aligned Pt-decorated $\mathrm{MoS}_{2}$ nanosheets coated on $\mathrm{TiO}_{2}$ nanotube arrays enable high-efficiency solar-light energy utilization for photocatalysis and self-cleaning SERS devices, Nano Energy 71 (2020) 104579, https://doi.org/10.1016/j.nanoen.2020.104579.

[40] S. Wang, J. Cai, J. Mao, S. Li, J. Shen, S. Gao, J. Huang, X. Wang, I. P. Parkin, Y. Lai, Defective black $\mathrm{Ti}^{3+}$ self-doped $\mathrm{TiO}_{2}$ and reduced graphene oxide composite nanoparticles for boosting visible-light driven photocatalytic and photoelectrochemical activity, Appl. Surf. Sci. 467-468 (2019) 45-55, https://doi.org/10.1016/j.apsusc.2018.10.138.

[41] T. Zhu, Y. Cheng, J. Huang, J. Xiong, M. Ge, J. Mao, Z. Liu, X. Dong, Z. Chen, Y. Lai, A 
transparent superhydrophobic coating with mechanochemical robustness for anti-icing, photocatalysis and self-cleaning, Chem. Eng. J. 399 (2020) 125746, https://doi.org/10.1016/j.cej.2020.125746.

[42] J. Huang, J. Shen, S. Li, J. Cai, S. Wang, Y. Lu, J. He, C. J. Carmalt, I. P. Parkin, Y. Lai, $\mathrm{TiO}_{2}$ nanotube arrays decorated with $\mathrm{Au}$ and $\mathrm{Bi}_{2} \mathrm{~S}_{3}$ nanoparticles for efficient $\mathrm{Fe}^{3+}$ ions detection and dye photocatalytic degradation, J. Mater. Sci. Technol. 39 (2020) 28-38, https://doi.org/10.1016/j.jmst.2019.04.043.

[43] J. Yu, S. Xiang, M. Ge, Z. Zhang, J. Huang, Y. Tang, L. Sun, C. Lin, Y. Lai, Rational construction of $\mathrm{LaFeO}_{3}$ perovskite nanoparticle-modified $\mathrm{TiO}_{2}$ nanotube arrays for visiblelight driven photocatalytic activity, Coatings 8 https://doi.org/10.3390/coatings8110374.

[44] J. Cai, F. Shen, Z. Shi, Y. Lai, J. Sun, Nanostructured $\mathrm{TiO}_{2}$ for light-driven $\mathrm{CO}_{2}$ conversion into solar fuels, APL Mater. 8 (2020) 040914, https://doi.org/10.1063/1.5144106.

[45] Z. Wu, L. Li, T. Liao, X. Chen, W. Jiang, W. Luo, J. Yang, Z. Sun, Janus nanoarchitectures: From structural design to catalytic applications, Nano Today 22 (2018) 62-82, https://doi.org/10.1016/j.nantod.2018.08.009.

[46] J. Cai, J. Shen, X. Zhang, Y. H. Ng, J. Huang, W. Guo, C. Lin, Y. Lai, Light-driven sustainable hydrogen production utilizing $\mathrm{TiO}_{2}$ nanostructures: A review, Small Methods 3 (2019) 1800184, https://doi.org/10.1002/smtd.201800184.

[47] B.C. Kim, E. Jeong, E. Kim, S.W. Hong, Bio-organic-inorganic hybrid photocatalyst, $\mathrm{TiO}_{2}$ and glucose oxidase composite for enhancing antibacterial performance in aqueous environments, Appl. Catal. B: Environ. 242 (2019) 194-201, https://doi.org/10.1016/j.apcatb.2018.09.102.

[48] U. Siripatrawan, P. Kaewklin, Fabrication and characterization of chitosan-titanium dioxide nanocomposite film as ethylene scavenging and antimicrobial active food packaging, Food Hydrocolloid. 84 (2018) 125-134, https://doi.org/10.1016/j.foodhyd.2018.04.049.

[49] D. Miao, Z. Huang, X. Wang, J. Yu, B. Ding, Continuous, spontaneous, and directional water transport in the trilayered fibrous membranes for functional moisture wicking textiles, Small 14 (2018) 1801527, https://doi.org/10.1002/smll.201801527.

[50] L.-X. Liu, W. Chen, H.-B. Zhang, Q.-W. Wang, F. Guan, Z.-Z. Yu, Flexible and multifunctional silk textiles with biomimetic leaf-like mxene/silver nanowire nanostructures for electromagnetic interference shielding, humidity monitoring, and self-derived hydrophobicity, Adv. Funct. Mater. 29 (2019) 1905197, https://doi.org/10.1002/adfm.201905197.

[51] Y. Xu, J. Sheng, X. Yin, J. Yu, B. Ding, Functional modification of breathable polyacrylonitrile/polyurethane/ $/ \mathrm{TiO}_{2}$ nanofibrous membranes with robust ultraviolet resistant 
and waterproof performance, J. Colloid Interface Sci. 508 (2017) 508-516, https://doi.org/10.1016/j.jcis.2017.08.055.

[52] C.H. Xue, S.T. Jia, H.Z. Chen, M. Wang, Superhydrophobic cotton fabrics prepared by sol-gel coating of $\mathrm{TiO}_{2}$ and surface hydrophobization, Sci. Technol. Adv. Mater. 9 (2008) 5, https://doi.org/10.1088/1468-6996/9/3/035001.

[53] F. Xu, I. Gough, J. Dorogin, H. Sheardown, T. Hoare, Nanostructured degradable macroporous hydrogel scaffolds with controllable internal morphologies via reactive electrospinning, Acta Biomater. 104 (2020) 135-146, https://doi.org/10.1016/j.actbio.2019.12.038.

[54] M.L. Wang, K. Wang, Y.Y. Yang, Y.N. Liu, D.G. Yu, Electrospun environment remediation nanofibers using unspinnable liquids as the sheath fluids: A review, Polymers 12 (2020) 13, https://doi.org/10.3390/polym12010103.

[55] C.-K. Huang, K. Zhang, Q. Gong, D.-G. Yu, J. Wang, X. Tan, H. Quan, Ethylcellulose-based drug nano depots fabricated using a modified triaxial electrospinning, Int. J. Biol. Macromol. 152 (2020) 68-76. https://doi.org/10.1016/j.ijbiomac.2020.02.239.

[56] Y. Bai, D. Wang, Z. Zhang, J. Pan, Z. Cui, D.G. Yu, S.-W. Annie Bligh, Testing of fast dissolution of ibuprofen from its electrospun hydrophilic polymer nanocomposites, Polymer Testing, 93 (2021) 106872. https://doi.org/10.1016/j.polymertesting.2020.106872.

[57] S. Kang, S. Hou, X. Chen, D.G. Yu, L. Wang, X. Li, G.R. Williams, Energy-saving electrospinning with a concentric Teflon-core rod spinneret to create medicated nanofibers. Polymers 12 (2020) 2421, https://doi.org/10.3390/polym12102421.

[58] S. Chang, M. Wang, F. Zhang, Y. Liu, X. Liu, D. Yu, H. Shen, Sheath-separate-core nanocomposites fabricated using a trifluid electrospinning, Mater. Des. 192 (2020) 108782, https://doi.org/10.1016/j.matdes.2020.108782.

[59] X. Yang, L. Yan, F. Ran, A. Pal, J. Long, L. Shao, Interface-confined surface engineering constructing water-unidirectional Janus membrane, J. Membr. Sci. 576 (2019) 9-16, https://doi.org/10.1016/j.memsci.2019.01.014.

[60] M. Wang, D.-G. Yu, X. Li, G.R. Williams, The development and bio-applications of multifluid electrospinning, Mater. Highlights 1 (2020) 1, https://doi.org/10.2991/mathi.k.200521.001.

[61] A.C. Daly, L. Riley, T. Segura, J.A. Burdick, Hydrogel microparticles for biomedical applications, Nat. Rev. Mater. 5 (2019) 20-43, https://doi.org/10.1038/s41578-019-0148-6.

[62] J. Yan, M. Bloom, S.C. Bae, E. Luijten, S. Granick, Linking synchronization to self-assembly using magnetic Janus colloids, Nature 491 (2012) 578-581, https://doi.org/10.1038/nature11619.

[63] L.D. Zarzar, V. Sresht, E.M. Sletten, J.A. Kalow, D. Blankschtein, T.M. Swager, Dynamically reconfigurable complex emulsions via tunable interfacial tensions, Nature 518 (2015) 520-524, https://doi.org/10.1038/nature14168. 
[64] R. Wang, K. Lan, Z. Chen, X. Zhang, C.-T. Hung, W. Zhang, C. Wang, S. Wang, A. Chen, W. $\mathrm{Li}, \mathrm{X}$. Xu, D. Zhao, Janus mesoporous sensor devices for simultaneous multivariable gases detection, Matter 1 (2019) 1274-1284, https://doi.org/10.1016/j.matt.2019.07.004.

[65] S. Gao, X. Dong, J. Huang, J. Dong, F. D. Maggio, S. Wang, F. Guo, T. Zhu, Z. Chen, Y. Lai, Bioinspired soot-deposited Janus fabrics for sustainable solar steam generation with saltrejection, Glob. Chall. 3 (2019) 1800117, https://doi.org/10.1002/gch2.201800117.

[66] M. Wang, D. Li, J. Li, S. Li, Z. Chen, D.G. Yu, Z. Liu, J.Z. Guo, Electrospun Janus zein-PVP nanofibers provide a two-stage controlled release of poorly water-soluble drugs, Mater. Des. 196 (2020) 109075, https://doi.org/10.1016/j.matdes.2020.109075.

[67] Y. Liu, X. Liu, P. Liu, X. Chen, D.G. Yu, Electrospun multiple-chamber nanostructure and its potential self-healing applications, Polymers 12 (2020) 2413, https://doi.org/10.3390/polym12102413.

[68] Z. Zhu, Z. Liu, L. Zhong, C. Song, W. Shi, F. Cui, W. Wang, Breathable and asymmetrically superwettable Janus membrane with robust oil-fouling resistance for durable membrane $\begin{array}{llllll}\text { distillation, } & \text { J. } & \text { Membr. } & \text { Sci. } & 563 & \text { (2018) }\end{array}$ https://doi.org/10.1016/j.memsci.2018.06.028.

[69] C. Zhang, Y. Nie, S. Sanvito, A. Du, First-principles prediction of a room-temperature ferromagnetic Janus VSSe monolayer with piezoelectricity, ferroelasticity, and large valley polarization, Nano Lett. 19 (2019) 1366-1370, https://doi.org/10.1021/acs.nanolett.8b05050.

[70] H. Hu, L. Wu, Y. Tan, Q. Zhong, M. Chen, Y. Qiu, D. Yang, B. Sun, Q. Zhang, Y. Yin, Interfacial synthesis of highly stable $\mathrm{CsPbX}_{3} /$ oxide janus nanoparticles, J. Am. Chem. Soc. 140 (2018) 406-412, https://doi.org/10.1021/jacs.7b11003.

[71] Z. Huang, Y. Quan, J. Mao, Y. Wang, Y. Lai, J. Zheng, Z. Chen, K. Wei, H. Li, Multifunctional superhydrophobic composite materials with remarkable mechanochemical robustness, stain repellency, oil-water separation and sound-absorption properties, Chem. Eng. J. 358 (2019) 1610-1619, https://doi.org/10.1016/j.cej.2018.10.123.

[72] P. Zhou, J. Lv, H. Xu, X. Wang, X. Sui, Y. Zhong, B. Wang, Z. Chen, X. Feng, L. Zhang, Z. Mao, Functionalization of cotton fabric with bismuth oxyiodide nanosheets: Applications for photodegrading organic pollutants, UV shielding and self-cleaning, Cellulose 26 (2019) 28732884, https://doi.org/10.1007/s10570-019-02281-8.

[73] T.K. Jana, S.K. Jana, A. Kumar, K. De, R. Maiti, A.K. Mandal, T. Chatterjee, B.K. Chatterjee, P. Chakrabarti, K. Chatterjee, The antibacterial and anticancer properties of zinc oxide coated iron oxide nanotextured composites, Colloid Surf. B-Biointerfaces 177 (2019) 512-519, https://doi.org/10.1016/j.colsurfb.2019.02.041.

[74] S. Banerjee, D.D. Dionysiou, S.C. Pillai, Self-cleaning applications of $\mathrm{TiO}_{2}$ by photo-induced hydrophilicity and photocatalysis, Appl. Catal., B 176 (2015) 396-428, https://doi.org/10.1016/j.apcatb.2015.03.058. 
[75] Y. Xu, W. Wen, J.M. Wu, Titania nanowires functionalized polyester fabrics with enhanced photocatalytic and antibacterial performances, J. Hazard. Mater. 343 (2018) 285-297, https://doi.org/10.1016/j.jhazmat.2017.09.044.

[76] G.Q. Gu, C.B. Han, J.J. Tian, T. Jiang, C. He, C.X. Lu, Y. Bai, J.H. Nie, Z. Li, Z.L. Wang, Triboelectric nanogenerator enhanced multilayered antibacterial nanofiber air filters for efficient removal of ultrafine particulate matter, Nano Res. 11 (2018) 4090-4101, https://doi.org/10.1007/s12274-018-1992-1.

[77] Y. Yang, S. Chang, Y. Bai, Y. Du, D.-G. Yu, Electrospun triaxial nanofibers with middle blank cellulose acetate layers for accurate dual-stage drug release, Carbohydr. Polym. 243 (2020) 116477, https://doi.org/10.1016/j.carbpol.2020.116477.

[78] J. Hou, J. Yang, X. Zheng, M. Wang, Y. Liu, D.-G. Yu, A nanofiber-based drug depot with high drug loading for sustained release, Int. J. Pharm. 583 (2020) 8, https://doi.org/10.1016/j.ijpharm.2020.119397.

[79] K. Wang, P. Wang, M. Wang, D.-G. Yu, F. Wan, S.W.A. Bligh, Comparative study of electrospun crystal-based and composite-based drug nano depots, Mater. Sci. Eng. C 113 (2020) 110988, https://doi.org/10.1016/j.msec.2020.110988.

[80] Y. Ding, C. Dou, S. Chang, Z. Xie, D.G. Yu, Y. Liu, J. Shao, Core-shell Eudragit S100 nanofibers prepared via triaxial electrospinning to provide a colon-targeted extended drug release, Polymers 12 (2020) 2034, https://doi.org/10.3390/polym12092034.

[81] M. Wang, J. Hou, D.G. Yu, S. Li, J. Zhu, Z. Chen, Z. Electrospun tri-layer nanodepots for sustained release of acyclovir, J. Alloy. Compd. $846 \quad$ (2020) 156471, https://doi.org/10.1016/j.jallcom.2020.156471.

[82] J. Yang, K. Wang, D.-G. Yu, Y. Yang, S.W.A. Bligh, G.R. Williams, Electrospun Janus nanofibers loaded with a drug and inorganic nanoparticles as an effective antibacterial wound dressing, Mater. Sci. Eng. C 111 (2020) 110805, https://doi.org/10.1016/j.msec.2020.110805.

[83] W.D. Huang, X. Xu, H.-L.Wang, J.X. Huang, X.-H. Zuo, X.-J. Lu, X.-L. Liu, D.G.Yu, Electrosprayed ultra-thin coating of ethyl cellulose on drug nanoparticles for improved sustained release, Nanomaterials 10 (2020) 1758, https://doi.org/10.3390/nano10091758.

[84] K. Wang, H. Wen, D.G. Yu, Y. Yang, D. Zhang, Electrosprayed hydrophilic nanocomposites coated with shellac for colon-specific delayed drug delivery, Mater. Des. 143 (2018) 248-255, https://doi.org/10.1016/j.matdes.2018.02.016.

[85] J.Y. Huang, S.H. Li, M.Z. Ge, L.N. Wang, T.L. Xing, G.Q. Chen, X.F. Liu, S.S. Al-Deyab, K.Q. Zhang, T. Chen, Y.K. Lai, Robust superhydrophobic $\mathrm{TiO}_{2} @$ fabrics for uv shielding, selfcleaning and oil-water separation, J. Mater. Chem. A 3 (2015) 2825-2832, https://doi.org/10.1039/C4TA05332J.

[86] P. Roach, N.J. Shirtcliffe, M.I. Newton, Progess in superhydrophobic surface development, Soft Matter 4 (2008) 224-240, https://doi.org/10.1039/b712575p. 
[87] H. Wang, Z. Liu, E. Wang, X. Zhang, R. Yuan, S. Wu, Y. Zhu, Facile preparation of superamphiphobic epoxy resin/modified poly(vinylidene fluoride)/fluorinated ethylene propylene composite coating with corrosion/wear-resistance, Appl. Surf. Sci. 357 (2015) 229235, https://doi.org/10.1016/j.apsusc.2015.09.017.

[88] C.Y. Xing, J.P. Guan, Y.J. Li, J.Y. Li, Effect of a room-temperature ionic liquid on the structure and properties of electrospun poly(vinylidene fluoride) nanofibers, ACS Appl. Mater. Interfaces 6 (2014) 4447-4457, https://doi.org/10.1021/am500061v.

[89] Y. Guo, X. Zhang, Y. Wang, W. Gong, Q. Zhang, H. Wang, J. Brugger, All-fiber hybrid piezoelectric-enhanced triboelectric nanogenerator for wearable gesture monitoring, Nano Energy 48 (2018) 152-160, https://doi.org/10.1016/j.nanoen.2018.03.033.

[90] T. Boccaccio, A. Bottino, G. Capannelli, P. Piaggio, Characterization of pvdf membranes by vibrational spectroscopy, J. Membr. Sci. 210 (2002) 315-329, https://doi.org/10.1016/s03767388(02)00407-6.

[91] H. Wang, R. Wang, L. Sun, Z. Liu, Y. Zhu, Y. Zhu, Mechanical and tribological characteristics of carbon nanotube-reinforced polyvinylidene fluoride (PVDF)/epoxy composites, RSC Adv. 6 (2016) 45636-45644, https://doi.org/10.1039/c6ra00577b.

[92] B. Deng, M. Yu, X.X. Yang, B.W. Zhang, L.F. Li, L.D. Xie, J.Y. Li, X.F. Lu, Antifouling microfiltration membranes prepared from acrylic acid or methacrylic acid grafted poly(vinylidene fluoride) powder synthesized via pre-irradiation induced graft polymerization, J. Membr. Sci. 350 (2010) 252-258, https://doi.org/10.1016/j.memsci.2009.12.035.

[93] L.H. Lou, J.L. Wang, Y.J. Lee, S.S. Ramkumar, Visible light photocatalytic functional $\mathrm{TiO}_{2} /$ pvdf nanofibers for dye pollutant degradation, Part. Part. Syst. Charact. 36 (2019) 12, https://doi.org/10.1002/ppsc.201900091.

[94] J. Bae, Y. Kim, H. Kim, Y. Kim, J. Jin, B.S. Bae, Ultraviolet light stable and transparent solgel methyl siloxane hybrid material for uv light-emitting diode (uv led) encapsulant, ACS Appl. Mater. Interfaces 7 (2015) 1035-1039, https://doi.org/10.1021/am507132a.

[95] X.F. Gao, L. Jiang, Water-repellent legs of water striders, Nature 432 (2004) 36-36, https://doi.org/10.1038/432036a.

[96] N. Hamzah, C.P. Leo, Membrane distillation of saline with phenolic compound using superhydrophobic pvdf membrane incorporated with $\mathrm{TiO}_{2}$ nanoparticles: Separation, fouling and self-cleaning evaluation, Desalination 418 (2017) 79-88, https://doi.org/10.1016/j.desal.2017.05.029.

[97] D.M. Lin, X.R. Zeng, H.Q. Li, X.J. Lai, T.Y. Wu, One-pot fabrication of superhydrophobic and flame-retardant coatings on cotton fabrics via sol-gel reaction, J. Colloid Interface Sci. 533 (2019) 198-206, https://doi.org/10.1016/j.jcis.2018.08.060. 
[98] Y. Si, Q. Fu, X. Wang, J. Zhu, J. Yu, G. Sun, B. Ding, Superelastic and superhydrophobic nanofiber-assembled cellular aerogels for effective separation of oil/water emulsions, ACS Nano 9 (2015) 3791-3799, https://doi.org/10.1021/nn506633b.

[99] J. Hu, J. Lin, Y. Zhang, Z. Lin, Z. Qiao, Z. Liu, W. Yang, X. Liu, M. Dong, Z. Guo, A new anti-biofilm strategy of enabling arbitrary surfaces of materials and devices with robust bacterial anti-adhesion via a spraying modified microsphere method, J. Mater. Chem. A 7 (2019) 26039-26052, https://doi.org/10.1039/C9TA07236E.

[100] J. Lin, X. Chen, C. Chen, J. Hu, C. Zhou, X. Cai, W. Wang, C. Zheng, P. Zhang, J. Cheng, Z. Guo, H. Liu, Durably antibacterial and bacterially antiadhesive cotton fabrics coated by cationic fluorinated polymers, ACS Appl. Mater. Interfaces 10 (2018) 6124-6136, https://doi.org/10.1021/acsami.7b16235.

[101] P.V.L. Reddy, B. Kavitha, P.A.K. Reddy, K.H. Kim, $\mathrm{TiO}_{2}$-based photocatalytic disinfection of microbes in aqueous media: A review, Environ. Res. 154 (2017) 296-303, https://doi.org/10.1016/j.envres.2017.01.018.

[102] J. Podporska-Carroll, E. Panaitescu, B. Quilty, L. Wang, L. Menon, S.C. Pillai, Antimicrobial properties of highly efficient photocatalytic $\mathrm{TiO}_{2}$ nanotubes, Appl. Catal. B: Environ 176-177 (2015) 70-75, https://doi.org/10.1016/j.apcatb.2015.03.029.

[103] H. Lin, W. Deng, T. Zhou, S. Ning, J. Long, X. Wang, Iodine-modified nanocrystalline titania for photo-catalytic antibacterial application under visible light illumination, Appl. Catal. B: Environ 176-177 (2015) 36-43, https://doi.org/10.1016/j.apcatb.2015.03.039.

[104] K. Rasool, M. Helal, A. Ali, C.E. Ren, Y. Gogotsi, K.A. Mahmoud, Antibacterial activity $\begin{array}{lllll}\text { of } & \mathrm{Ti}_{3} \mathrm{C}_{2} \mathrm{Tx} & \mathrm{Tx} & \mathrm{A} & \end{array}$ https://doi.org/10.1021/acsnano.6b00181.

[105] K.M. Soto, C.T. Quezada-Cervantes, M. Hernandez-Iturriaga, G. Luna-Barcenas, R. Vazquez-Duhalt, S. Mendoza, Fruit peels waste for the green synthesis of silver nanoparticles with antimicrobial activity against foodborne pathogens, LWT-Food Sci. Technol. 103 (2019) 293-300, https://doi.org/10.1016/j.lwt.2019.01.023.

[106] Y. Cheng, H. Yang, Y. Yang, J. Huang, K. Wu, Z. Chen, X. Wang, C. Lin, Y. Lai, Progress in $\mathrm{TiO}_{2}$ nanotube coatings for biomedical applications: A review, J. Mater. Chem. B 6 (2018) 1862-1886, https://doi.org/10.1039/C8TB00149A.

[107] M. Ge, Y. Tang, O. I. Malyi, Y. Zhang, Z. Zhu, Z. Lv, X. Ge, H. Xia, J. Huang, Y. Lai, $X$. Chen, Mechanically reinforced localized structure design to stabilize solid-electrolyte interface of the composited electrode of $\mathrm{Si}$ nanoparticles and $\mathrm{TiO}_{2}$ nanotubes, Small 16 (2020) 2002094, https://doi.org/10.1002/smll.202002094. 